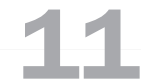

\title{
FROM THE GRAIN TO THE PIXEL, AESTHETIC AND POLITICAL CHOICES
}

Nadine Wanono

By considering the evolution of some technical aspects of film culture and industry, the idea was on the one hand to concentrate on the role and place of mechanical aspects in our discipline, and on the other hand to demonstrate how technical choices could help us to resolve the challenging question of the representation of time in a documentary narrative manner. I will examine how fieldwork, feedback, and analysis of a few specific rituals organized in the Dogon country forced me to reconsider the treatment of the representation of time and space in my ethnographic documentaries. After realizing how deeply these contradictions forced me to reconsider my methodology and my technical choices, I chose to concentrate on digital programing as a possible language to address this challenging topic and to offer possibilities to propose new forms of representations.

In the event, by considering the role and place of digital programing as a language to create new forms of representation, I realized how techniques had been isolated from the social and cultural context they emerged from.

By comparing the notion of grain that came from the analog film industry to the one of pixels which came out of the digital era, the purpose was to underline the aesthetic and political choices embedded in this technical criteria and how the spectators, whatever their age, could create or recreate their time perception according to the resonance of the grain or the pixel, from the viewpoint of a personal and social imaginary construction.

\section{Dogon Fieldwork and Feedback}

Trained as a visual anthropologist, I spent long periods of time in Dogon country, sharing the daily life activities of the women and filming their ongoing actions. One of the films I made on my own as a camera person and film-maker dealt with 
the rituals following the birth of a baby. When I decided to concentrate on this specific aspect of women's life, I had already spent almost ten years traveling back and forth between Sanga and Paris. During this time, I had also become a mother. When I went back to Dogon country in 1989, with my one-year-old baby boy, my girlfriends told me they finally perceived me as a woman, since before that I was perceived as an asexual person; leaving my family, my parents, living on my own for several months seemed to them more masculine than feminine. My status, until then, had always been unclear.

This situation explained the feeling and the challenge you are faced with when you spend several months in the middle of a Dogon village. Surprisingly enough, it was quite difficult for me to render all these emotions in the final editing of the film. To obtain a scientific label from the academic system requires you to follow implicit and very specific rules and to adapt consequently your own creativity and interpretation. You inevitably have to thoroughly erase all the emotional aspects, the personal dimension, and any subjective accounts, at least in a French academic context.

In order to analyze the birth ritual, I filmed for a month. It took me quite a long time to understand the structure, the different steps, and especially the specific moment when the ritual started. I conducted several surveys in order to complete as precisely as I could the unfolding process. In short, I eventually could say that the whole process starts at the birth of the future mother and after families have decided to marry their sons and daughters to each other. From that specific moment, numerous exchanges of gifts, sacrifices, and rituals could be done in favor of the future wife's family. To understand the naming process celebrated after three weeks of reclusion of the mother and her baby, it was necessary to perceive that the ongoing process started almost 18 or 19 years earlier.

I could offer the same analysis regarding our perception of space in a filmic narrative and the way Dogon people consider their space, the crucial separation between the bush and the village, the space occupied by the wilderness and the space somehow structured by men.

When I clearly realized the gap existing between my filmic narrative, which introduced a linear perspective of time, and the time period at stake understanding the relationship between the families and the place of the newborn in the village, I was quite disappointed and realized how much the film represented our own perception of a society, through our own codes, rules, and technics; it was like a two-way mirror.

\section{From the Anthropology Department to the Media Art and Technology Program}

From this obvious and painful acknowledgment of failure and obsessed with the question of space and time representation in my documentary, I decided to follow 
new paths by leaving the anthropological "structure" for a transdisciplinary program held in the Media Art and Technology edifice at UCSB.

I decided to concentrate on more experimental ways to represent these essential cultural aspects. I produced two experimental pieces during a workshop organized by Marcos Novak. From these experiments I started to consider programing as a language with creative power.

During this interdisciplinary workshop led by Marcos Novak, the professionally recognized artist who created the concepts of virtual architecture and liquid architecture, I have been introduced to a new trajectory into his work which deals with the epistemological changes that digital technology has provoked. Transvergence is one of the concepts around which Novak structured our workshop. He opposes transvergence to convergence and divergence. The last two notions are "simple linear extrapolations that proceed by strategies of alignment, transvergence advances translinearly by tactics of derailment. ... While convergence and divergence contain the hidden assumption that the true, in either a cultural or an objective sense, is a continuous landmass, transvergence recognizes true statements to be islands in an alien archipelago, sometimes only accessible by leaps, flights, and voyages on vessels of artifice." As Novak explains: "tranvergence, in a pedagogical and research context, refers to the study and applications of concepts and methods by which convergence of disciplines, media and technologies is seen not as a goal in itself, not as the focal point of a predictable origin for divergences but as an opportunity to speculate and propose novel transdisciplinary epistemological and creative formations. Using willful strategies of derailment, it seeks to promote the mergence of previously unattainable but presently potentially viable species of efforts: future genres, future fields of inquiry, future arts, media and sciences."

We reconsidered, for example, the notion of "duende," beauty, subjectivity, and the difference between invention, discovery, and creation. In parallel I discovered notions such as Autopoiesis, a process whereby an organization produces itself and constitutes itself in space, e.g. biological cell, living organism, and some extend a corporation or a society; Alloselves for the concept of putting together two antithetic notions: the alien as the other belonging to an other order entirely and the self or the reflexive. As author of this alien, the alloself is derived from our own understanding of what self and consciousness may involve. Transmodernity is characterized, for Novak, by the extensive and deliberate production of an extreme form of the other; Accretion an agglomerate of material or cells, and the Entanglement, concept which comes from Quantum Mechanics, refers to the state of separate particles, which are mutually interdependent even if they exist at great distance from each other. We discovered the structures of the infinity small, the nature of new species, and the survival attitudes of parasites in order to transmit the diversity and the complexity of structures that already exist. This intense experience was not a just another instance of the usual repetitive process that academic teaching is based on. We were in a creative process, experiencing somehow the apodictic aesthetic, which was at times provocative, making us 
experience a "necessary discomfort". As the main goal of Novak's workshop was to produce objects, shapes, and a network as a kind of embodiment of our research, I did some detailed research into the questions of translation.

If the visual anthropologist, facing the task of translating audiovisual data into words, tries to translate her materiel with a software other than Word? What will be the gain? Can we imagine a new open space, next to the books, the articles, and the bibliography where students and anthropologists could produce queer objects?

I quickly understood this apprehension of computing language also with Lisa Jevbratt and Geogres Legady who, each of them at different levels, gave me the opportunity to collaborate with digital artists to conceive and create specific prototypes.

With a very simple algorithm conceived by a colleague from Media Art and Technology department, one sequence of my film on the baby naming ritual was integrated into a software algorithm and the deformation of the pictures introduced the spectator to a complete abstract reality. Simultaneously, the sound was amplified and reproduced through software and the spectators could play around with the sound intensity by waving their hands near the loudspeakers. By placing their hands nearer and nearer the loudspeaker the pictures became more and more abstract, reaching at some point a new sense of space, like the bush. The pictures indeed looked like particles of sand. It left the description process to enter in a creation process where the texture, the colors, the rhythm, the dynamic could change and the spectators could interact with all these elements.

These successive translations of my material were an attempt to shape and visualize them in accordance with their, so called, irrational dimension (see Figure 11.1).

Probably the obvious transformation and the distance between the original and the reproduction could provoke some uneasiness in some of us. Personally it is this friction between different levels of realities, which could give a new dimension to my work.

Even if this experiment was more than modest and aesthetically very basic, I realized how programing could be a language in itself for social scientists, and it became obvious that we needed to be trained to program ourselves or at least to have academic structures where the collaboration with programers or digital artists could be promoted.

This intensive experimentation over a period of six months on the specific role and power of the techniques in our discipline convinced me of the embarrassment of social sciences regarding the technical apparatus of our research. Ideas, concepts, and analysis seemed free from all kinds of technical constraints and remained completely outside our field of interest.

Trained by Jean Rouch, I remembered well the close links he established between the technical apparatus and the specific narrative he decided to unfold. We could quote, for example, the importance of the lens used by Michel Brault during filming of Chronicles of a Summer, or the way Rouch related the times spent rewinding his 


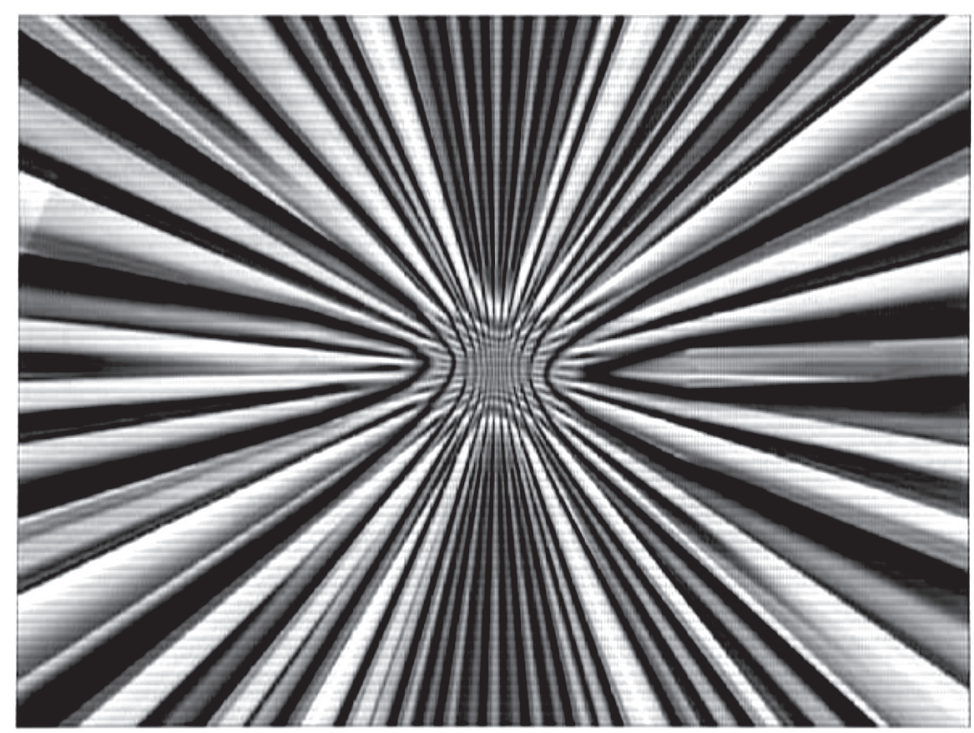

Figure 11.1 Interactive Composition Conceived by Andi Sojamo from Ibani or the Blue Scarf film of Nadine Wanono, () N. Wanono

small Bell \& Howell camera as a necessary time gap to conceive his next shots. I should add the distaste and frontal opposition he sometimes manifested towards video, which was closely linked to the fact he couldn't have any further kind of control on the microprocessor behind each element of the camera or the sound equipment. Also, he was closely linked to the aesthetics of grain and its political dimension. Ritually Rouch sat in the second row either at la Cinémathèque française or at the Musée de l'Homme in order to be "in" the screen, to perceive the grainy aspect of the high speed black and white stock and the texture of the projector screen.

\section{Concepts of Approach Techniques}

These different experiences developed over time, have led me to consider the links uniting the cinematic and technical act with the knowledge-production device. Indeed, the camera as a technical apparatus allows the production of theories and diverging interpretations concerning its possibilities as Schneider and Wright (2006) underlined it. ${ }^{3}$

The History of Technology as presented by Singer, Hall, and Holmyard (1954), ${ }^{4}$ or more recently by Bertrand Gille (1978), ${ }^{5}$ alludes clearly to the fact that objects are divided and classified in accordance with their technical characteristics which make up coherent wholes of compatible structures. While looking in depth at the fabrication process, these analyses completely forget about the objects' relation to the cultural, economic, and sociological worlds. As shown by Feenberg (1995) in 
The Politics of Knowledge, ${ }^{6}$ Technique is a medium fully integrated in the everyday life of modern societies: important technical changes thus have a direct impact on economy, politics, religion, and culture.

The merging of the Science of Technique with the Humanities was not an obvious step and occurred only in a late phase of their development; as Philippe Bruneau notes in his article Histoire des techniques, ergologie, archéologie, "Technique is a distinct and independent branch of Reason and thus is no more foreign to humankind than logic, ethnicity or ethics." In fact, Bruneau makes the point that some areas are neglected by the history of techniques, like, for example, "architecture, image, writing, music in favor of the production of Raw materials and foodstuffs ..." 8

For Gille, ${ }^{9}$ one needs to analyze the technical and economic systems because the adoption of a technical construction necessarily leads to the adoption of a social system corresponding to it in order for coherence to be maintained. This line of thought is the one that Bruno Bachimont ${ }^{10}$ and Georges Simondon ${ }^{11}$ largely build upon.

If one accepts that Technique and Device are linked to the socio-economic reality that surrounds them, one is able to approach the idea of "machinic layout" coined by Felix Guattari. ${ }^{12}$ He calls for the need to save and enhance the processes of transversal singularization which should be able to escape mercantile standardization in order to better communicate political, social, or economic questions as well as techno-scientific transformations and artistic creation.

The video camera or programing codes illustrate perfectly this layout that all the subjective or ideological powers have given room for the "machine fictionnante" as Bruno Bachimont calls it: "Technique becomes fictionnante (or "fictionning") not only when it allows for the materialisation of an idea but when it becomes a machine or a device with the possibility to create fiction in itself. What symbolic nature shows us is the boundless creativity of inscribing techniques". ${ }^{13}$ Subjectivity is thus always a process that is elaborated between social systems of differing sizes and that is lived and experienced by individuals in their singular existences. Each one can allow himself to be influenced passively by the modes of subjectivity that are offered him, or claim for himself the building blocks of subjectivity in order to put together a creative process of singularization.

With the notion of layout, Guattari expresses the way in which an object, individual or collective is "produced," in part, by technical devices that are themselves made up of diverse types of machines: "technical machines, economic writing machines but also conceptual machines, religious machines, aesthetic machines, perceptive machines, desiring machines ..."14

Digital code is, in fact, both a physical input into a system and a symbolic expression needing interpretation. It leads to deep changes in the basis of our thought and action devices and mechanisms. Lev Manovich, in The Language of New Media $^{15}$ affirms that to understand the logic of new media one should investigate the field of computer science for the "new terms, categories, and operations that 
characterise media and that become programmable." 16 This is a call for software as logos. It attempts to solidify theory by giving it a specific direction - the logic and objects of software.

Chun proposes the acceptance of code as a resource, a perspective that "enables us to think in terms of the gap between source and execution."17 This gap seemingly includes, or perhaps is, the "borderland" that in Hayles signifies materiality, "the connective tissue joining the physical and mental, the artifact and the user." ${ }^{18}$ When Chun identifies the 'code as re-source' perspective, positioning an "interface as a process rather than as a stable thing," it resonates with Simondon and the transduction concept: it is a physical, biological, mental, or social operation, by which an activity propagates itself from one element to the next, within a given domain, and bases this propagation through structuring the domain, something that moves from one place to another; each area of the constituted structure serves as the principle and the model for the next area, as a primer for its constitution, to the extent that the modification expands progressively at the same time as the structuring operation. $^{19}$

Aware of what is at stake on the epistemological level and of the consequences they can have on the social and political spheres, I have centered my research on the values and beliefs imparted to the technologies of the mind or to the cultural technologies in the way Stiegler ${ }^{20}$ uses the term, meaning the convergence of the audiovisual, telecommunications, and information technologies.

To tackle this cross-disciplinary approach I organized my research project around the links between certain technologies of knowledge (video camera, microscope, telescope, programing codes) and the concepts they engender, the impact of historical, political, and economic conditions on their use and on their positions in popular imagination. I will be focusing in particular on the aesthetic and technical notion of grain, commonly used during the analog era, and the pixel as a notion which has already undermined several layers of sensibility, ways of life, style and film dynamics.

By going from analog technologies to digital ones, the concepts offered to define them and our modes of relating to these knowledge mediums will be revisited and looked at transversally. Achieving this will then allow us to underline the break lines, continuities, and structures of the hopes, aspirations, and fears that these technologies awaken in us.

\section{The Grain: Aesthetic and Political Choices}

=Shiny or grainy? Probably for the young generation the shiny aesthetics of the digital flat screen and of the digital technologies at large couldn't help them to understand the political and aesthetical battle around the choice of grain.

From the type of stock, the quality of the light and right to the choice of equipment, every single option in the mise en scène was a meaningful step for the film-makers involved in documentary and more specifically in ethnographic film. 
Michel Brault, Ricky Leacock, and John Marshall, as camera persons for their own documentaries, chose the freedom to move, the freedom to be as close as possible to their subjects by refusing supposedly sophisticated equipment: they affirmed very vigorously their position.

We can quote Richard Leacock:

\begin{abstract}
The next step in my de-professionalization came a few weeks later, when Roger Tilton came to me with what seemed at that time to be a wild idea. He wanted to make a short film about an evening at a dance hall in New York's East Village: A wild evening of Dixieland Jazz. He had spoken to several cameramen and they had all told him that the only way to do it was with the big studio cameras, the microphone boom, the clap sticks, setting up and shooting each individual shot-the same old routine. Roger refused to agree to this. A kindred spirit! So I agreed to try making this film the way we had filmed combat ... We shot wild! No tripod! Move! Shoot! I was all over the place, having the time of my life, jumping, dancing, shooting right in the midst of everything. We spent a fabulous evening shooting to our hearts' content... Tilton tells me that he was invited out to Hollywood by the biggies, but when he told them that they couldn't do this sort of thing with their clumsy equipment they told him to get lost and didn't even pay his fare back!21
\end{abstract}

Also see Figure 11.2.

This short story represents clearly the political situation in Hollywood, in the film industry and in major companies. We experienced the same problem as numerous young film-makers who decided to use the Super $8 \mathrm{~mm}$ format to produce documentary: the rules promulgated by the television system and the festivals encouraged films made with much more expensive and specific equipment, thus preventing film-makers from outside the business system to distribute their films, which were able to challenge not only the power of the film industry but also the rules established by the unions.

This event took place in 1954, and if we move further in time we could refer to Blow Up (1966), the Antonioni film, which deals with the relationship between the perceiving subject and the perceived object. Without describing the whole film, the story is about a still photographer who, during a photo session in the

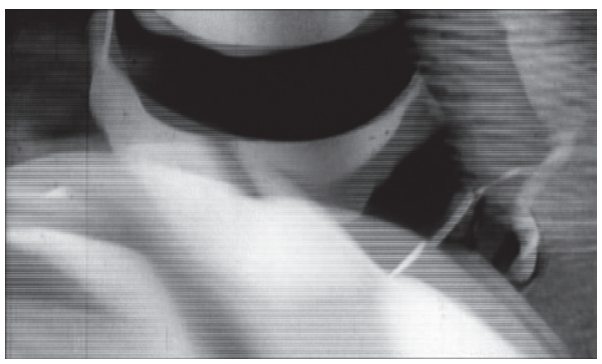

Figure 11.2 Rhythm. From the film Jazz Dance, (C) Canarybananafilms. 
middle of a London park, unconsciously witnesses a crime. He slowly realizes what happened during this photo session and decides to blow up the photo in order to see properly what is behind the apparent reality. By playing around with the notion of perception and the embedded meaning in the grain resolution of the photo, Antonioni as a film-maker is offering a challenge to the spectators who are watching two stories unfolding at the same time. The narrative is structured on the perception and their possible interpretations but also on the space notion blown up into a time relationship. In 1966, Michelangelo Antonioni said about Blow Up, "I think this is another way of making cinéma vérité-to endow a person with a story, that is, with the story which corresponds to their appearance, to their position, their weight, the volume they occupy in a particular space."22 As Colin Gardner explains, ${ }^{23}$ "In fact, the brute reality must first be textualized trough the storyboarding of the photographs before it can offer up meaning. The meaning of the whole situation is thereby inextricably constructed as a clear interpretation of the real, as well as an embodied memory." Seymour Chatman, ${ }^{24}$ for example, argues that there is a direct parallel between Thomas's (photographer) and Antonioni's enunciative practice as the film's ostensible author. Both activities involve the creation/production of filmic interpretation. Thus Chatman describes the photographs saying: "Indeed, much of the film can be seen as an account of the artist's effort to textualize a puzzling experience ... Narration is both the readiest and the most dramatic way of explaining an otherwise incomprehensible group of events."

The sequence also affords Antonioni the opportunity to comment on the hermeneutic nature of the apparatus's memory. This is what we could call the central perceptual studium of the film. Thus, in one instance, Thomas enlarges a detail of one photo against his enlargement screen, projecting the light of his enlarger onto the carefully positioned emulsion paper. This acts as a static parallel to the actual movement of the film we are watching projected, as light, onto the cinema screen, the site of our viewed vision. Thomas stands in relation to us as the spectator of a viewed vision, just as the enlargement stands in relation to Blow $U_{p}$ itself.

This intersection of viewing and viewed visions within the all-encompassing field of the apparatus is a profound one, because it reiterates the visible/invisible chasm that we have already discussed. We and Thomas can see the apparatus from which he creates his enlargement, but only we are aware of another (invisible) apparatus that makes Thomas's image possible at all: the cinema projector and screen.

Within these examples the grain from a political to an aesthetic affirmation gains its autonomy as part of an active and powerful element of the mise en scène.

The Pixel

As the grain is almost the smallest part of the film stock, the pixel can be perceived as the smallest visible element of the code language. ${ }^{25}$ In order to explain my 
position and the comparison I established between both these structures belonging to the world of technique, I have to refer to the artwork of two digital artists, Lisa Jevbratt and Hee Won Lee.

The former established in an article the clear difference between writing and programing. The writing process of words and sentences could produce literacy and poetry but coding, she added, created reality. "It is similar to the act of making a sculpture or designing and sewing clothes-to start with a material and feel how it folds and falls and cutting out two dimensional surfaces, that turn into three dimensional shapes by sewing them together in a specific way." She pursued her thought process by creating a word, the infome, "to denote this all-encompassing network environment/organism that consists of all computers and code language." "The term is derived from the word 'information' and the suffix 'ome,' which is used in biology and genetics to mean the totality of something as in chromosome. Within the Infome, artist programmers are more landscape-artists than writers, software is more like earthworks than narratives. The 'soil' we move, displace and map is not the soil created by geological processes. It is made up of language, communication protocols and written agreements." 26 The pixel could have some kind of autonomy and Lisa Jevbratt illustrated it perfectly when she worked on the data visualization as an indexical trace of the reality, an imprint.

She conceived "Mapping the Web Infome" (see Figure 11.3) project which consisted of software that she made in 2001 with some help of students and friends, and the "crawler" could visualize several types of information activities on the internet. You could search by name, by webpage or by acronym and have some indexical information resulting from this search engine. She collaborated with ten artists, one of whom was Lev Manovich, who decided to aestheticize the software activity in itself, and to interpret the visualization of the mapping as paintings created by information space in the software. When you clicked on each pixel, the IP address appeared as well as the country where the information came from. The person using this crawler could decide which colors, which shape, which formal representation could be used to represent this reality. For Jevbratt ${ }^{27}$ these lines, dots, bits, pixels were not representations of a reality: they were reality. We could see them as objects for interpretation but not interpretations. They stuck to the real ... On a more basic level it allows the image to teach us something about the data, it allows us to use our vision to think (see Figure 11.4). On another level it makes the visualizations function as art in more interesting ways, connecting them in various ways to artistic traditions from pre-modern art such as cave paintings, to abstract expressionism, color-filled minimalism, to post-structuralist deconstructions of power structures embedded in data. The visual appearance that follows is very "plain." It is strict and "limited" in order not to impose its structure on its possible interpretations and meanings. "The visualizations avoid looking like something we have seen before or they playfully allude to some recognizable form yet slip away from it. Viewed from outside the Infome, from where we stand, they are abstractabstract realism." 28 


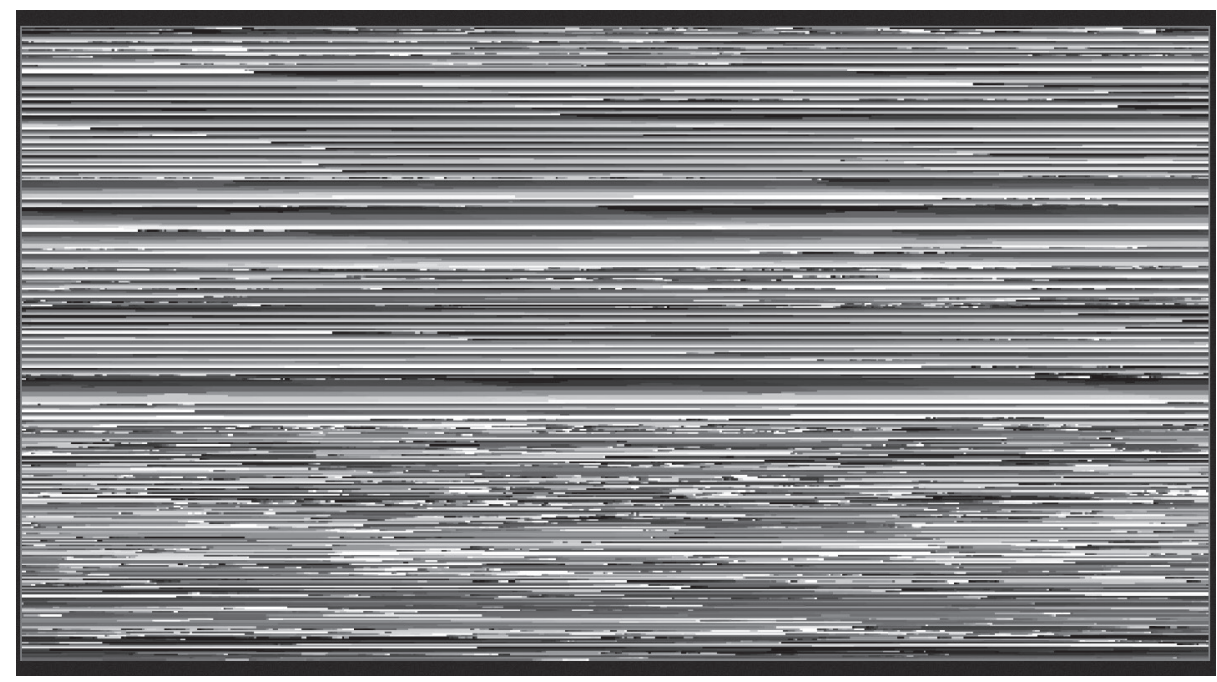

Figure 11.3 The Crawler, (C) Mapping the Web Infome by Lisa Jevbratt.

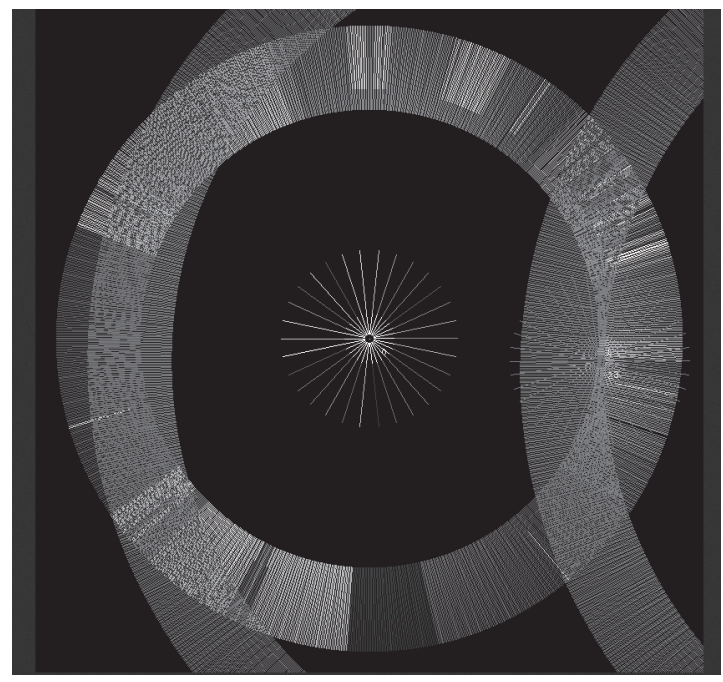

Figure 11.4 Data Beautiful by Lev Manovich, () Mapping the Web Infome by Lisa Jevbratt.

A few years later, during an encounter called Singular Narrativities organized at Le Cube, ${ }^{29}$ we presented Phone Tapping made by Hee Won Lee.

The film is constructed from that single, imperceptible instant which signals the shift from day to night, a fleeting moment in which what was is no more, where things might acquire fresh significance. Voices guide us through the city while the camera seems to be searching for a specific plot of land, for the coincidence between narrative and image. The topography of the site continues to advance, while in parallel there emerges a second topography-mental this time-until, perhaps, they meet, somewhere here, in a new psychical space. Using the city of 
Seoul, and using personal stories that are being told, the spectator's role is to follow it and select a locus of interpretation: truth, urban folktale. With Phone Tapping, we are faced with our own fantasy interacting with a reality that keeps evaporating and being reconstructed ... we are dissolved while simultaneously constructing ourselves and propelling our desires beyond what the image shows us.

The pixels were not just independent elements with an autonomous power of constructing or deconstructing your perception of the reality (see Figure 11.5). They also gave you the possibility to engage with your own insight of time and space. At the personal level, this film was a concrete shift in term of sensibility: the shiny aesthetic closely integrated with the globalized digital devices could give rise to a singular approach of your own perception of the real. It was promising from an aesthetical point of view but also from a "New Wave" point of view. Just as in 1960, the emergence of the "French New Wave" in cinema was linked to a new kind of equipment but also to the necessity of deconstructing reality as shown by the mainstream film industry. Now, from 2012, many digital artists are engaged in this challenging reconstruction of the real. They are inspired by different aesthetic languages, political analysis, social backgrounds, but are also convinced of the necessity to introduce queer objects into the field, to challenge its boundaries and limitations.

In this specific case, the programing language introduced us to the pixel as a particular identity but also as an autonomous character. Grain or pixel could be equally perceived as narrative choice. In In The Name of Love, a Michel Leclerc film, there are three different types of film used: first, the fake Super- 8 archive images which were intended to match the real Super- 8 archive of the Algerian War. Then,

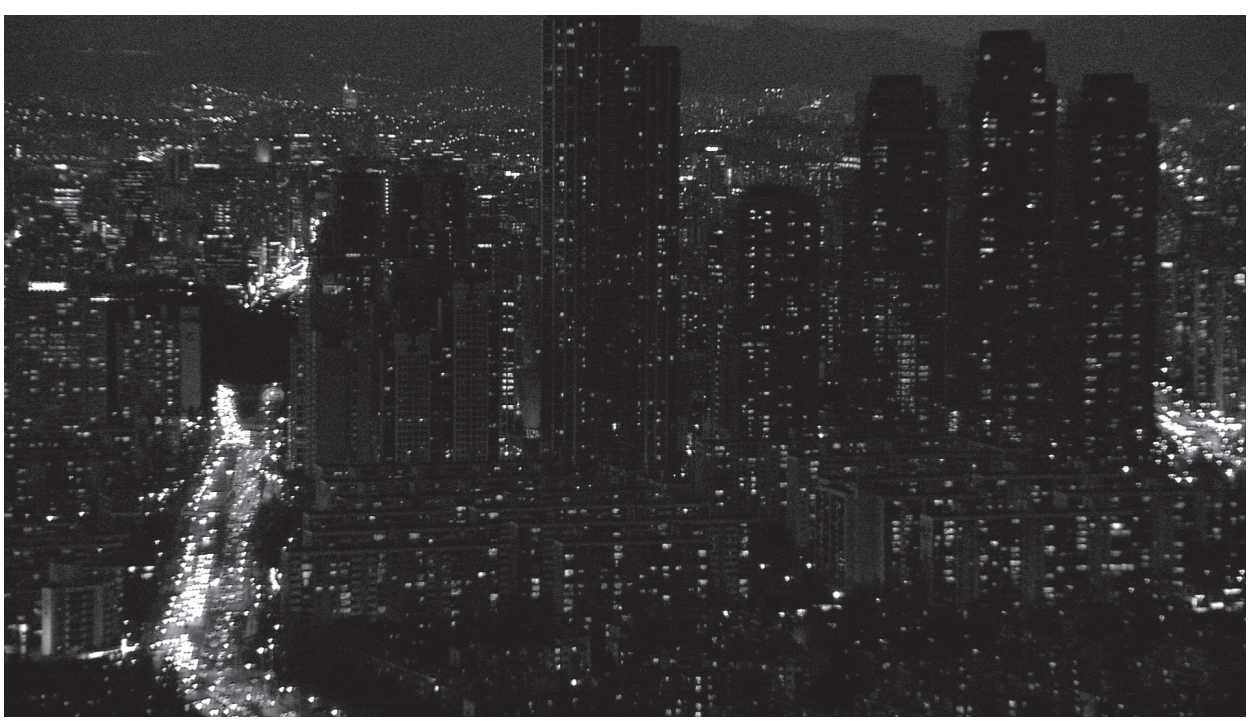

Figure 11.5 Urban folktale in Pixels. Phone Tapping @ Hee-won Lee and Le Fresnoy-Studio national. 
the wedding of Bahia's parents, which was designed to also look like Super 8 family footage. ${ }^{30}$ Finally, there are the subjective visions of the characters, which are distinguished from the other fictional images via the change in texture of the image. It is this textural change, the appearance of the grain, and the colorimetric modifications that precisely represent this subjectivity in the images. The film-maker tried to recreate the grainy aspect of the analog stock with a digital device and admitted it was not successful. To obtain the grain aspect and its metaphoric dimension, he decided to use a real Super- $8 \mathrm{~mm}$ camera.

From another perspective, it is very interesting to underline how critics can present and analyze specific characters in fiction film. I would like to refer for example to Collateral (2004), a film by Michael Mann. From the analysis of this film, one could say that in his mind, Vincent, one of the characters, is representative of the digital age: his binary, trenchant side (yes or no, dead or alive, target or attacker), the fact that he has a very modern mindset (the post-yuppie sociopath out of a novel by Brett Easton Ellis, as Vincent Malausa described it) and all the computer equipment he uses. Max, another character, with his "cool," more traditional personality would be the representative of the analog world. In the same spirit, we could quote the book In the Beginning ... Was the Command Line by Neal Stephenson, which illustrates and reveals in a hilarious and provocative way, how an operating system tyrannizes and downloads popular revelations. The author, by making the comparison between car brand reputation and operating systems, portrayed characters who behave like a Mac OS Operating system or a Microsoft Operating System. For Stephenson, "ever since the Mac came out, our operating systems have been based on metaphors, and anything with metaphors in it is fair game as far as I'm concerned ..."

"In retrospect, this was telling me two things about peoples' relationships to technology. One was that romance and image go a long way towards shaping their opinions. If you doubt it (and if you have a lot of spare time on your hands) just ask anyone who owns a Macintosh and who, on those grounds, imagines himself or herself to be a member of an oppressed minority group. The other, somewhat subtler point, was that interface is very important. Imagine a crossroads where four competing auto dealerships are situated. One of them (Microsoft) is much, much bigger than the others. It started out years ago selling three-speed bicycles (MS-DOS); these were not perfect, but they worked, and when they broke you could easily fix them. There was a competing bicycle dealership next door (Apple) that one day began selling motorized vehicles-expensive but attractively styled cars with their innards hermetically sealed, so that how they worked was something of a mystery." ${ }^{31}$

These different examples illustrate the close relationship between our perception of the real through technical objects or devices and how we could identify ourself with it.

I'm not sure we could affirm that the hand-held camera and the grainy pictures were politically more engaged than the shiny digital pictures being produced today, 
but the relationship between the film-maker and his or her equipment, the political surrounding and the economic dimension clearly influenced our perception of what could be seen as political engagement. Without going back to the history of specific equipment such as the Super-8, for example, we should remind ourselves that this amateur hand-held camera was released for a family purpose and deeply rooted within the middle-class American family. It was intentionally diverted from its original utilization by independent film-makers to give credit not only to a political discourse but also to a very specific movement with Super- 8 film festivals all over the world.

By concentrating on this comparison between pixel and grain, my goal was to underline the crucial importance of taking into account on the one hand the technical aspects of the apparatus surrounding our work, and on the other hand discourses surrounding their capacities. As we are in our academic system in a permanent interface with techniques, it is time to consider it as part of our values, our ways of thinking and our way of imagining and dreaming. As we are dealing permanently with a very difficult and challenging task in order to translate from one culture to another the significance, the relationship people entertain within the real, we should therefore be aware of the close intricacy between technical discourse and scientific discourse and their respective power to guide and/or overwhelm our own imagination.

\section{Filmography}

Blow Up, 1966, Michelangelo Antonioni, Italy, UK, 110 mins.

Collateral, 2004, Michael Mann, Paramount Pictures and DreamWorks SKG, $120 \mathrm{~mm}$.

Ibani or the Blue Scarf, naming ritual of a Dogon baby, 1991, Nadine Wanono, CNRSIMages, République du Mali France, 51 mn, 16 mm, DVCAM, English and French subtitles.

In the Shadow of the Sun, Arou Hogon's funeral and enthronement ritual, 1997, Nadine Wanono and Philippe Lourdou, La Sept-Arte, CNRSImages, République du Mali, $83 \mathrm{mn}, 16 \mathrm{~mm}$, Video, English and French subtitles.

Jazz Dance, 1954, Roger Tilton, 20 mn, 35 mm.

Phone Tapping, 2009, Hee-won Lee, Studio Le Fresnoy, Corée du Sud, 9 mins 30 seconds, Experimental video.

The Name of Love, 2010, Michel Leclerc, Delante Films, Karé Productions, 100 mins.

\section{Notes}

1. M. Novak, Speciation, Transvergence, Allogenesis, Notes on the Production of the Alien, 2004, from http:// www.mat.ucsb.edu/ marcos/transvergence.pdf (accessed December 13, 2013). 
2. Idem.

3. A. Schneider, and C. Wright, "The Challenge of Practice," in Arnd Schneider and Christopher Wright (eds.) Contemporary Art and Anthropology (Oxford: Berg, 2006).

4. C. Singer, A. R. Hall, and E. J. Holmyard, History of Technology (Oxford and New York: Oxford University Press, 1954).

5. B. Gille, Histoire des Techniques (Paris: Gallimard Coll La pleiade, 1978).

6. A. Feenberg, and A. Hannay, Technology and the Politics of Knowledge (Bloomington, IN: Indiana University Press, 1995).

7. P. Bruneau, "Histoire des techniques, ergologie, archéologie," in Jean-Pierre Brun and Philippe Hockey (eds) Techniques et Sociétés en Méditerranée (Aix-en-Provence: Maison méditerranéenne des sciences de l'homme, 20111 , 35.

8. Ibid. 31.

9. Gille, Histoire des Techniques, 31.

10. Bruno Bachimont, Le sens de la technique: Le numérique et le calcul, Encre marine (Paris: Editions les Belles Lettres, 2010).

11. Georges Simondon, L'individuation psychique et collective (Aubier, 1989).

12. Felix Guattari, L'inconscient machinique, Essai de Schizon-analyse (Paris: Editions Recherches, 1979).

13. Bruno Bachimont, Connaissance, activité, organisation (Paris: La Découverte, 2004).

14. Guattari, L'inconscient machinique, 183.

15. L. Manovich, The Language of New Media (Cambridge, MA: MIT Press, 2001).

16. Manovich, The Language of New Media, 48.

17. W. H. K. Chun, "On 'Sourcery,' or Code as Fetish," Configurations, 16 (3), 2008, 299-324.

18. N. K. Hayles, Nanoculture: Implications of the New Technoscience (Bristol: Intellectual Books, 2004), 72.

19. G. Simondon, The Position of the Problem of Ontogenesis, trans. Gregor Flanders, parrhesiajournal. org, 7, 2009, 11, from http://parrhesiajournal.org/parrhesia07/parrhesia07_simondon 1.pdf (accessed December 31, 2013).

20. B. Stiegler B., Technics and Time, 1-The Fault of Epimetheus, trans. Richard Beardsworth and George Collins (Stanford, CA: Stanford University Press, 1998).

21. http://www.richardleacock.com/Jazz-Dance (accessed December 31, 2013).

22. Michelangelo Antonioni, "Reality and Cinema-Verite," in Blow-Up (London: Lorrimer, 1971), 13.

23. C. Gardner, C., Antonioni's Blow Up and the Chiasmus of Memory, from http://www.artbrain. org/antonionis-blow-up-and-the-chiasmus-of-memory (accessed December 31, 2013).

24. Seymour Chatman, Antonioni or The Surface of the World (Berkeley and Los Angeles, CA: University of California Press, 1985), 149.

25. From Webopedia: Short for Picture Element, a pixel is a single point in a graphic image. Graphics monitors display pictures by dividing the display screen into thousands (or millions) of pixels, arranged in rows and columns. The pixels are so close together that they appear connected.

26. L. Jevbratt, "Coding the Infome: Writing Abstract Reality," Dichtung Digital, 2003, from http:// www.dichtung-digital.de/2003/3-jevbratt.htm (accessed December 31, 2013).

27. Ibid

28. Ibid.

29. This event took place during the Thirtieth Bilan du Film Ethnographique. Jacques Lombard, President du Comité du Film Ethnographique and myself as Secrétaire Générale both conceived and organized this event, in order to encourage new forms of structure in ethnographic film. 
30. I took these examples from a master held by François Belin at Ecole Louis Lumière and entitled Image argentique/image numérique: hybridations esthétiques, mélange des moyens de captation au sein d'un film.

31. Neal Stephenson, In the Beginning was the Command Line (New York: Avon, 1999). 